\title{
Estimating the impact of understaffing on sales and profitability in retail stores
}

\author{
Vidya Mani \\ Smeal College of Business, Pennsylvania State University, State College, PA 16802 \\ vmani@psu.edu
}

Saravanan Kesavan

Kenan-Flagler Business School, University of North Carolina at Chapel Hill, Chapel Hill, NC 27599

skesavan@unc.edu

\section{Jayashankar M. Swaminathan}

Kenan-Flagler Business School, University of North Carolina at Chapel Hill, Chapel Hill, NC 27599

msj@unc.edu

\begin{abstract}
In this paper we use micro-level data on store traffic, sales and labor from 41 stores of a large retail chain to identify the extent of understaffing in retail stores and quantify its impact on sales and profitability. We show how traffic data can be leveraged in making staffing decisions through use of a structural model that captures the relationship between traffic, sales and labor. Assuming that store managers aim to maximize profits, we estimate the contribution of labor to sales and impute the cost of labor for each store in our sample. We find significant heterogeneity in the contribution of labor to sales as well as imputed cost of labor across these stores and across time. Using the estimated parameters, we establish the presence of systematic understaffing during peak hours. Aligning staffing levels with changing traffic patterns can result in a $6.15 \%$ savings in lost sales and a $5.74 \%$ improvement in profitability. We describe a pilot implementation of our approach at another large retailer where we identify periods of understaffing in their stores and document the impact on conversion rate and lost sales.
\end{abstract}

Key words: data analytics, retail staffing, structural estimation, store performance 


\section{Introduction}

The ability to meet shifting customer demand in a timely and cost-effective manner is an important driver of retail store performance. Retailers need to match in-coming traffic with labor to provide a consistent quality of service to their customers. This has led many retailers to invest in customer-facing technologies to gain access to micro-level data on customer behavior, such as customer arrival patterns, in each of their stores. However, to improve their service quality, retailers need business analytical tools that will effectively utilize these traffic data to deliver insights useful to improve staffing decisions. In the absence of such business analytical tools, retailers would face the common problem of "drowning in numbers but lacking in insight" (Fisher and Raman, 2010, p4). In this paper, we present an approach that enables a retailer to effectively utilize customer traffic data to develop a robust staffing plan for each individual store.

Devices that track customer traffic in a store have evolved over the years from simple counting instruments to highly refined thermal imaging technologies These devices are now able to provide a realtime count of incoming customers to a store in as small as 15 minute intervals. Popular vendors in this market are ShopperTrak, SMS, SensorSource, Traf-Sys etc. Some of the retailers actively tracking customer traffic include high-end fashion retailers (e.g. Prada USA, Neiman Marcus), furniture retailers (e.g. Ashley Furniture, La-Z-Boy), and electronic retailers (e.g. HH Gregg, Apple). Most retailers tend to use traffic data to track store performance metrics like traffic growth, conversion rate and basket value. These performance metrics are then used to measure efficacy of marketing campaigns and to compensate store managers. The opportunity to use traffic data to improve labor planning remains largely unexplored.

Recent academic research suggests that store traffic data may be useful to improve staffing decisions. Perdikaki et al. (2012) show that $1 \%$ increase in labor results in a $0.5 \%$ increase in conversion rate in women's apparel stores while Ton (2009) finds that a one standard deviation increase in labor at a store is associated with a $10 \%$ increase in profit margin over the course of the year. However, it is unclear how retailers should go about increasing labor. An across the board increase in labor is unlikely to be optimal. One approach would be to use store traffic data to identify hours when a store is understaffed and increase labor during those hours. Alternatively, retailers may determine if there are hours when the store is overstaffed so they could reallocate labor from those periods to hours when their store is understaffed. In this paper, we present a methodology that utilizes traffic data to identify periods during a day when a store is overstaffed and periods when it is understaffed.

Understaffing and overstaffing during different times of the day occur due to several reasons including lack of flexibility and forecast errors (Lam et al. 1998; Quan 2004). First, employers need to provide minimum shift lengths to their employees either due to quality of life considerations or due to union rules or state laws. Due to the minimum shift length requirements, managers may be reluctant to 
schedule additional employees for short periods of time to meet peak demand. Second, store traffic is unpredictable leading to forecast errors that result in erroneous staffing decisions. Thus understaffing and overstaffing at the hourly level will occur in retail stores even if managers were optimally planning the store labor at the daily level. Though understaffing and overstaffing are normally expected in any retail store, the extent of under- and over- staffing and their impacts on performance has not been studied so far

Overstaffing could lower profits because of higher labor costs. Understaffing, on the other hand, could impact both short-term as well as long-term profitability. In the short-term, understaffing could result in customers turning back without purchasing, and over the long-term it may result in customers switching to competitors due to poor service. Dissatisfied customers may also express their discontent at other forums, including social networking websites such as Facebook and Twitter, causing retailers to worry about the negative word-of-mouth effect (Park et al. 2010). Understaffing also negatively impacts store associate satisfaction (Loveman 1998) and decline in employee satisfaction has been linked to decline in store's financial performance (Maxham et al. 2008). Thus the negative impact of understaffing is potentially much higher than that of overstaffing.

Our aim in this paper is to leverage detailed traffic data, combine it with point-of-sale (PoS) data on sales and transactions, and labor data to estimate the extent of understaffing and overstaffing in a retail setting and estimate their short-term impacts on sales and profitability. We use hourly data collected over a period of 1 year from 41 stores of a large specialty apparel retail chain, Alpha ${ }^{l}$. The relationship between store traffic, sales and labor are captured in a structural model through a sales response function and a cost function. The sales response function helps us determine how traffic and labor contribute to revenue while the cost function helps us determine the imputed cost of labor used by store managers to make their labor decisions. We use structural estimation techniques to determine the parameters of the sales response function and cost function from the data. Since the sales response function and cost function could vary by store and time, our estimation is performed separately for each individual store and separately for weekdays and weekends. By allowing for heterogeneity in the estimated parameters across stores and time, we implicitly capture the difference in underlying customer traffic patterns at different stores. Using each store's sales response function and cost function, we construct the optimal labor plan for each store, and explore the extent and impact of the deviation between the actual labor and the optimal plan.

A fundamental challenge in structural estimation is ensuring that the underlying structural model reflects economic realities of the decision maker. We undertook several measures to ensure our model validity. First, our underlying model is derived from prior literature (Lam et al. 1998) to increase external validity. Second, we conduct hypotheses testing to examine if the parameters from the underlying model

\footnotetext{
${ }^{1}$ The identity of the retailers have been disguised to maintain confidentiality
} 
are consistent with economic behavior of operating managers identified in prior literature. Third, we use field data from another retailer, Beta, to further validate our model. Specifically, a managerial intervention around staffing in one of the stores provides a unique natural experiment to examine if the model parameters and level of understaffing from before and after the intervention are consistent with expected behavior.

We have the following results in our paper. First, we find significant understaffing during a threehour peak period in all 41 stores of our sample. Second, we estimate the impact of understaffing on lost sales to be $6.15 \%$ and that on profitability to be $5.74 \%$, while the impact of overstaffing on profitability is estimated to be $2.04 \%$. Third, we find that the imputed cost of labor used by managers when making their staffing decisions exhibits considerable heterogeneity across stores due to local market characteristics.

This paper makes the following contributions to the growing research on use of micro-level data in managerial decision making in the retail sector. First, like Alpha and Beta, many retailers are still in the process of determining ways in which traffic data may be used to improve staffing decisions. By providing a methodology to identify hours when their stores are understaffed or overstaffed, our paper allows retailers to focus their attention on those limited periods when they need to improve their staffing decisions. Second, there is a long line of work in operations management that has employed linear programming or queuing theory for staffing decisions (Dantzig 1954; Holt et al. 1956; Gans et al. 2003). Implicit in these papers is the assumption that understaffing and overstaffing are costly to organizations. Our paper contributes to this literature by estimating the impact of understaffing and overstaffing on lost sales and profitability in the retail sector. We show that the impact of understaffing on profitability could be particularly large, even if one considers just the short-term impact. Third, our paper contributes to the emerging area of business analytics by demonstrating the value of data-driven decision making in the context of store staffing. We develop a structural model to capture the relationship between store performance, traffic, and labor in retailer Alpha and perform a pilot implementation at another retailer Beta to demonstrate how organizations can improve their staffing decisions. Finally, we contribute to the small but growing literature that empirically analyzes the heterogeneity in managerial decisions across different local markets and the importance of incorporating them in the decision-making process. Our study extends the findings of Campbell and Frei (2010) to the retail sector by showing that store managers take local market characteristics into account when staffing their stores.

\section{Literature Review}

Labor planning problems have long been studied in operations management. Starting with the seminal papers by Dantzig (1954) and Holt et al. (1956), several papers have developed mathematical models to improve staffing decisions. The objective of these papers is to minimize costs by minimizing the level of over and understaffing. Staffing problems have also been studied in other service systems like call center 
settings and health-care settings (Gans et al. 2003; Green 2004; Kc and Terwiesch 2009; He et al. 2012) where the objective is to find optimal staffing schedules that would minimize the waiting time and costs. Our paper contributes to this literature by providing an approach to quantify the extent of understaffing in retail stores and its impact on lost sales and profitability.

Empirical research examining the impact of labor on retail store performance has been gaining importance in the recent years. Several researchers have examined the impact of labor on store financial performance. Using data from a small-appliances and furnishing retailer, Fisher et al. (2007) find that store associate availability (staffing level) and customer satisfaction are among the key variables in explaining month-to-month sales variations. Netessine et al. (2010) find a strong cross-sectional association between labor practices at different stores and basket values for a supermarket retailer, and demonstrate a negative association between labor mismatches at the stores and basket value. Ton (2009) investigates how staffing level affects store profitability through its impact on conformance and service quality for a large specialty retailer. Using monthly data on payroll, sales and profit margins, Ton (2009) finds evidence that increasing labor leads to higher store profits primarily through higher conformance quality. Our paper differs from the above in its research question, data, and methodology. We use a structural estimation technique to investigate the prevalence of understaffing using hourly data on traffic, labor, and sales and quantify its impact on store profitability.

While numerous papers have utilized traffic data on incoming calls to study labor issues in the call center literature, the lack of traffic data has stymied research in labor issues faced by brick-and-mortar retailers. Lam et al. (1998), Lu et al. (2011), and Perdikaki et al. (2012) are notable exceptions. Lu et al. (2011) use video-based technology to compute the queue length in front of a deli counter at a supermarket and show that consumers' purchase behavior is driven by queue length and not waiting time. Perdikaki et al. (2012) characterize the relationships between sales, traffic, and labor for retail stores. They show that at an aggregate level, store sales have an increasing concave relationship with traffic; conversion rate decreases non-linearly with increasing traffic; and labor moderates the impact of traffic on sales. Our paper differs from Perdikaki et al. (2012) both in its objective and methodology. Our paper is closest to Lam et al. (1998) who study sales-force scheduling decisions based on traffic forecast. Similar to us, they quantify the impact of labor scheduling decisions on store profits. Their analysis was conducted using data from a single store. Our analysis is richer not only because of the use of panel data from 41 stores but also because of the methodology employed. We use a structural estimation technique to impute the cost of labor using past decisions of store managers while Lam et al. (1998) use accounting costs of labor elicited from the store manager to perform their analysis.

Our approach of imputing labor costs based on past labor decisions has several advantages. Prior research has shown that managers' perceptions of costs can be very different from traditional costs 
(Cooper and Kaplan, 1998; Thomadsen, 2005; Musalem et al. 2010). Also, researchers have advised caution when dealing with information elicited from managers as even experts tend to underestimate or overestimate the actual costs that should be considered in decision making (Hogarth and Makridakis, 1981; Kahneman and Lovallo, 1993). The use of structural estimation techniques to impute the underlying costs considered by managers in decision-making has only recently been adopted in operations management literature. This approach to estimate cost parameters from observed decisions in operations management has been utilized by Cohen et al. (2003), Hann and Terwiesch (2003), Olivares et al. (2008), and Allon et al. (2011). Cohen et al. (2003) impute the underlying cost parameters of a supplier's problem in the semiconductor industry, where a supplier optimally balances his cost of delay with the holding cost and cost of cancelation in deciding the time to begin order fulfillment. Hann and Terwiesch (2003) use transaction data on bidding to impute the frictional costs experienced by customers in an online setting. Olivares et al. (2008) look at cost parameters of the newsvendor problem in the context of hospital operating room capacity decisions, where the optimal capacity decision is obtained by balancing the cost of overutilization with the cost of underutilization. Allon et al. (2011) impute the cost placed by consumers on waiting time at different outlets of fast food drive-through restaurants. In particular, they consider location characteristics, competition and brand-specific characteristics in their estimation process and then use these parameters to study the effect of reducing waiting time on the firms' market shares. Ours is the first paper to impute costs in the context of retail labor planning. We show that the imputed cost of labor used by store managers varies significantly across stores and is driven by local market characteristics like competition, median household income, and availability of labor.

\section{Research Setting}

We obtained proprietary store-level data for Alpha, a women's specialty apparel retail chain. As of 2011, there were over 213 Alpha stores operating in 36 states, the District of Columbia, Puerto Rico, the U.S. Virgin Islands, and Canada. These stores are typically in high-traffic locations like regional malls and shopping centers.

Alpha's stores are typically less than 3500 sq. $\mathrm{ft}$ with small backrooms. Sales associates at Alpha are trained to provide advice on merchandise to customers, help ring up customers at the cash register, price items, and monitor inventory to ensure that the store is run in an orderly fashion. There is no differentiation in task allocation amongst the different store associates and they receive a guaranteed minimum hourly compensation as well as incentives based on sales. To emphasize the sales nature of their jobs, these associates are also called stylists. In line with the trendy clothes sold by this retailer, the job requirement states that store associates need to be fashion forward and should maintain their appearance in a way that represents their brand in a professional and fashionable manner. 
We illustrate the typical labor planning process for retailers in Figure 1. First, retailers determine the sales forecast for each store. The sales forecast is typically generated at an aggregate monthly or weekly level. The sales forecast for a store would take into account, among other factors, store specific characteristics, sales trends, new product introductions, seasonality, and upcoming promotions. Next, these sales forecasts are used to determine the aggregate number of labor hours required in a store. An important input to determining the appropriate level of labor is the knowledge of the marginal cost of labor. A profit maximizing retailer is expected to set labor at the point where marginal revenue is equal to the marginal cost of labor. Once the aggregate labor hours are determined, workers schedules are created after taking into account several constraints such as worker availability, minimum shift constraints, and other government and labor union constraints (Quan 2004).

While the labor planning process described above is typically similar across retailers, there is a wide variation in how it is executed. Many large big-box retail organizations use centralized planning tools from companies such as Kronos and RedPrairie to perform these planning activities and the store manager is only responsible for ensuring the compliance to labor plan. On the other hand, Alpha uses a centralized labor planning tool that generates weekly sales forecasts for each store. In addition, they also have traffic forecasts for each store. The store managers at Alpha use such data as an input to generate number of labor hours required for each day. This involves the managers' judgment around how much sales they can expect each day and how much labor would be required to support those sales activities. Store managers have strong incentives to control payroll expenses in their stores since their bonuses are tied to store profits. Hence store managers strive to increase sales while controlling payroll costs.

Alpha had installed traffic counters in 60 of its stores located in the United States during 2007. This advanced traffic-counting system guarantees at least $95 \%$ accuracy of performance against real traffic entering and exiting the store. This technology has the capability to distinguish between incoming and outgoing shopper traffic, count side-by-side traffic and groups of people, and differentiate between adults and children, while not counting shopping carts or strollers. The technology also can adjust to differing light levels in a store and prevent certain types of counting errors. For example, customers would need to enter through fields installed at a certain distance from each entrance of the store in order to be included in the traffic count, thus preventing cases in which a shopper enters and immediately exits the store from being included in actual traffic counts. It also provides a time stamp for each record that enables a detailed breakdown of data for analysis. The hourly traffic data along with performance metrics such as conversion rate (defined as the ratio of number of transactions to incoming traffic), basket value (defined as the ratio of sales volume to number of transactions), and the labor in the store were available to corporate headquarters as well as store managers at periodic intervals. We use the same data for our analysis. 


\subsection{Data Description}

Alpha's stores were open 7 days a week. Operating hours differed based on location as well as time period, e.g., weekdays and weekends. We obtained operating hours for each store and restricted our attention to normal operating hours. Of the 60 stores, five stores were in free-standing locations and five stores were in malls that did not have a working website to provide additional information needed to determine their operating hours. Moreover, there were nine stores, for which we did not have complete information for the entire year as they were either opened during the year or did not install traffic counters at the beginning of the year. Hence, we discard data from these 19 stores and focus on the remaining 41 stores that had complete information. These 41 stores are located across 17 states in the U.S in malls/shopping centers, and are of similar sizes.

Working with data from one retail chain allows us to implicitly control for factors such as incentive schemes, merchandise assortments, and pricing policies across stores. Data on factors such as employee training, managerial ability, employee turnover and manager tenure that could impact store performance are not available to us. We also do not possess information on inventory levels and promotions.

We obtained additional demographic information like the number of women apparel retail stores, total number of clothing stores, population, and median household income from EASI Analytics and Mediamark Research, Inc., which provide market research data collated from the Bureau of Economic Analysis (BEA), Bureau of Labor Statistics (BLS), and U.S. Census Bureau at the zip code level for each store.

\subsection{Sampling procedure}

Our data set consists of hourly observations from January to December, 2007. The retail industry displays significant seasonality in traffic patterns during the year (BLS, 2009) and the traffic pattern also varies considerably between weekdays and weekends. Such variations in traffic could be driven by changes in customer profile visiting the stores (Ruiz et al. 2004). In addition, retailers could react to such variations in traffic by changing the proportion of part-time workers. For example, Lambert (2008) finds that retailers tend to hire more part-time staff on weekends and holidays. Thus, the parameters of the sales response function and cost function could be different across these time periods. So, we identify subsamples in our dataset where we expect these parameters to be similar using hierarchical cluster analysis (Liu et al. 2010).

The results of the hierarchical cluster analysis for a representative store are shown in Figures 2a and 2b. Similar patterns were observed for rest of the stores in our sample as well. As shown in Figure 2a, there are two different clusters based on different days of the week, the first cluster corresponding to days of week, Monday-Thursday and the second cluster corresponding to the days of week, Friday-Sunday. Based on the different months of the year, as shown in Figure $2 b$, we observe two clusters, the first cluster 
consisting of months of January-November, and the second cluster with the month of December. Since we did not have sufficient observations in December to treat it as a separate sub-sample, we drop data from this month for the rest of our analysis. Next, we create two sub-samples using data from JanuaryNovember. The weekdays sub-sample is comprised of data from Monday, Tuesday, Wednesday, and Thursday and the weekends sub-sample comprises of data from Friday, Saturday, and Sunday. At this stage, we have 190 days in the weekday data set and 143 days in the weekend data set for each store.

We use the following notations: for store $i$, on day $t$ and hour $h, S_{i t h}$ denotes the dollar value of sales, $l_{i t h}$ denotes the persons per hour in the store, and $N_{i t h}$ denotes the store traffic or number of customers entering the store. After removing outliers based on top and bottom 5 percentile of sales and traffic, we had a total of 73,800 hourly observations for weekdays and 53,300 hourly observations for weekends. All further analyses were conducted on these datasets. Tables $1 \mathrm{a}$ and $1 \mathrm{~b}$ give a description of variable names, their definitions, and summary statistics of all store-related variables and demographic variables used in this study.

\section{Methodology and Estimation}

In this section we explain the methodology used to determine if retail stores are under or overstaffed. We determine a store to be understaffed in a given time period if it carries less than optimal labor in that time period. In order to determine the optimal labor, we extract the revenue function and cost function for each store. To do so, we assume that store managers make optimal labor decisions at an aggregate daily level and derive the revenue and cost functions for each store using historical daily data on sales, traffic, and labor. We justify this assumption based on the incentive structure of store managers whose bonuses are tied to store profits. Using the parameter estimates, we derive the optimal labor for each individual hour. The difference in actual labor and optimal labor is used to identify understaffing and overstaffing periods in the dataset.

In order to estimate the revenue function and cost function for each store, we make the following assumptions. First, we assume that the revenue function only depends upon the incoming traffic and amount of labor in the store. Second, we assume constant marginal cost of labor in our cost function. The manager knows this marginal cost when making staffing decisions but this cost is unobservable to the econometrician. We allow for marginal cost to vary across stores for the following reasons. First, some components of the accounting costs such as minimum wage rate, insurance, and medical benefits could vary across stores based on state laws in the United States. Thus stores within the same chain would be paying different wages for similar jobs. Second, the cost of labor could be driven by local market characteristics such as labor supply and customer expectations. Local markets with tight labor supply might face high employee turnover. High employee turnover increases labor costs due to increase in costs of hiring and training (Stiglitz 1974) and additional overtime costs till the vacancy is filled (Tziner and 
Birati 1996). Similarly, managers of stores that are located in markets where customers' expectation of service is higher might place greater emphasis on service level and assess lower costs to labor. For example, Campbell and Frei (2010) find that operating managers in a retail bank consider market-specific customer sensitivity to service time when they trade-off cost versus benefit of service to be provided. Finally, the cost of labor could depend upon the efficiency of labor and management in each store (Thomadsen 2005).

We use a structural estimation technique to determine the revenue and cost function for each store. Structural estimation techniques are useful to estimate unobservable or behavioral parameters (Reiss and Wolak 2007). A key decision in structural estimation is the choice of the underlying model that is used to capture managers' decision making process. Reiss and Wolak (2007) state that the choice of the structural model depends upon economic reality, data generating process, and ability to simplify estimation. We are guided by similar principles in our choice of the structural model. This retailer has a centrally planned tool that provides guidelines to the store managers, who then make the labor planning decisions. Prior empirical evidence on store manager incentives suggest that retailers develop incentive schemes for store managers with a goal of maximizing store profits (Dehoratius and Raman, 2007). In case of Alpha, store managers received an incentive compensation based on store profits. Hence, we argue that the store managers' labor decisions are taken with the goal of maximizing store profits ${ }^{2}$. However, it is challenging to elicit the exact mathematical structure that store managers use to make these labor decisions. Thus, we pursue the following approach. First, we impose a structure on the store managers' decisions based on an empirically validated model from literature and then test if the estimated parameters are consistent with prior findings.

In line with literature that has argued for external validity through use of models developed in other settings, we chose the model from Lam et al. (1998) as it closely matches the decision making environment of store managers in our setting. We provide further details in the next section.

\subsection{Structural Model}

First, we discuss the sales response model used in Lam et al. (1998) before presenting the profit function.

\section{Sales response model:}

From queuing theory, we know that an increase in the number of servers, or salespeople in our context, causes fewer customers to renege and consequently results in higher sales. Additionally, in a retail setting, it has often been observed that sales increases at a decreasing rate with traffic. Some causes

\footnotetext{
${ }^{2}$ It is common to assume profit maximization motive when estimating the behavioral parameters of managers. Such assumptions are required for structural model estimations. For example, Reiss and Wolak (2007) note "It is well known to economic theorists that without assumptions it is impossible to derive predictions about economic behavior (p. 4296)"
} 
for this include the negative effects of crowding on customers, having more browsers than buyers during peak hours and not having enough labor to satisfy the customer service requirements (Grewal et al. 2003). Theoretical literature in service settings has assumed a concave relationship between revenue and labor (Horsky and Nelson 1996; Hopp et al. 2007). This insight is reflected in recent empirical research as well. Both Fisher et al. (2007) and Perdikaki et al. (2012) provide evidence supporting this assumption and find sales to be a concave increasing function of the staffing level. The following modified exponential model, adapted from Lam et al. (1998), captures these relationships between store sales $\left(S_{i t}\right)$, store traffic $\left(N_{i t}\right)$, and number of sales associates $\left(l_{i t}\right)$ in a store $i$ on day $t$ :

$$
S_{i t}=\alpha_{i} N_{i t}^{\beta_{i}} e^{-\gamma_{i} / l_{i t}}
$$

where $\beta_{i}$ is the traffic elasticity, $\gamma_{i}$ captures the responsiveness of sales to labor (indirectly measuring labor productivity), and $\alpha_{i}$ is a store-specific parameter that captures the sales potential in the store. Here, overall store sales are positively associated with labor, but an increase in traffic and labor increases sales at a diminishing rate, i.e. $0<\beta_{i}<1, \gamma_{i}>1$.

Profit-maximization model:

We follow Lam et al. (1998) and assume a linear cost function for labor which leads to the following profit function:

$$
\pi_{i t}=S_{i t} * g_{i t}-l_{i t} * w_{i}
$$

where $\pi_{i t}$ is the gross profit net of labor costs, $S_{i t}$ is the overall dollar value of sales, $g_{i t}$ is the gross margin, $l_{i t}$ is the number of salespeople, and $w_{i}$ is the marginal cost of labor.

\section{Deriving the labor decision rule:}

Each store is expected to maximize the profit function in (2), yielding the following first-order condition for amount of labor to have in each store:

$$
\gamma_{i} \alpha_{i} N_{i t}^{\beta_{i}} e^{-\gamma_{i} / l_{i t}} g_{i t}=w_{i} l_{i t}^{2}
$$

Equation 3 is the decision rule for labor, and captures the way each store manager optimally balances the marginal cost and marginal revenue of having labor in the store. The optimal labor plan $\left(l_{i t}^{*}\right)$ is the value of labor that is a solution to Equation (3), given $\alpha_{i}, \beta_{i}, \gamma_{i}, w_{i}$ and store traffic $\left(N_{i t}\right)$.

\subsection{Estimating the marginal cost of labor}

Equations 1 and 3 serve as the basis for our estimation. In equation (3) we do not observe gross margin for each store at each time period. Since all stores sell similar assortments, we make a simplifying assumption that

$$
g_{i t}=g * \varepsilon_{i t}
$$

where $g$ is the gross margin of the retail chain. Substituting (4) in to (3) and dropping $g$ which is a constant, we obtain the following labor decision rule: 


$$
\gamma_{i} \alpha_{i} N_{i t}^{\beta_{i}} e^{-\gamma_{i} / l_{i t}} \varepsilon_{i t}=w_{i} l_{i t}^{2}
$$

One important challenge in estimating this regression is that of identification. We cannot distinguish $\gamma_{i}$ from $\alpha_{i}$ based on estimating the above equation alone. Consequently, we would be unable to determine all the parameters of the revenue function. To overcome this identification challenge, we utilize the sales data that we possess to estimate equation (1) and (5) simultaneously so we may add restrictions on our parameters which will help identify our parameters of interest. Numerous examples of using exclusion restrictions to overcome identification issues can be found in Wooldridge (2002).

We augment the sales model to control for day-of-week and month effects by including indicator variables for each day of the week (Monday-Thursday for weekdays and Friday-Sunday for weekends) and month of year (January - November). Our sales response function for store $i$ during time period $t$ is given by:

$$
S_{i t}=\alpha_{i} \alpha_{i m}{ }^{a} \alpha_{i d} a_{d} N_{i t}^{\beta_{i}} e^{-\gamma_{i} / l_{i t}} \varepsilon_{2 i t}
$$

where $d$ denotes the day of week, $m$ denotes the month of year, $a_{d}=1$ if day of week $d=1,0$ otherwise, and $a_{m}=1$ if month of year $m=1,0$ otherwise. We note that $\varepsilon_{1 i t}, \varepsilon_{2 i t}$ represent unit mean residuals for the labor decision rule and sales response function respectively, i.e., $E\left[\varepsilon_{1 i t}\right]=E\left[\varepsilon_{2 i t}\right]=1$.

We use generalized method of moments (GMM) technique to estimate equations 5 and 6 . The use of GMM estimation method is advantageous as it needs no additional assumptions concerning the specific distribution of the disturbance terms, and it allows us to handle any endogeneity issues that may arise in our estimation.

We apply logarithmic transformation to equations 5 and 6 to obtain the following two moment conditions:

$$
\begin{aligned}
& E\left[z_{1 i t}\left\{\log \left(\gamma_{i} \alpha_{i} \alpha_{i m}{ }^{a_{m}} \alpha_{i d} a_{d} N_{i t}^{\beta_{i}} e^{-\gamma_{i} / l_{i t}}\right)-\log \left(w_{i} l_{i t}^{2}\right)\right\}\right]=0 \text { i.e. } E\left[z_{1 i t} \vartheta_{2 i t}\right]=0 \\
& E\left[z_{2 i t}\left\{\log \left(S_{i t}\right)-\log \left(\alpha_{i} \alpha_{i m}{ }^{a_{m}} \alpha_{i d} a_{d} N_{i t}^{\beta_{i}} e^{-\gamma_{i} / l_{i t}}\right)\right\}\right]=0 \text { i.e. } E\left[z_{2 i t} \vartheta_{1 i t}\right]=0
\end{aligned}
$$

where $Z_{i t}=\left\{z_{1 i t}, z_{2 i t}\right\}$ represents the set of instruments and $\Theta=\left\{\alpha_{i}, \alpha_{i d}, \alpha_{i m}, \beta_{i}, \gamma_{i}, w_{i}\right\}$ represents the vector of parameters to be estimated. The above two equations are also known as the population moment conditions.

An important estimation issue that needs to be tackled is the determination of instruments. The instruments need to be such that they are correlated with the endogenous variable but uncorrelated with the error terms in both regressions. The correlation with the endogenous variable indicates the strength of the instrument variable and the lack of correlation with the error term indicates the exogeneity or validity of the instrument (Wooldridge 2002). As noted earlier, the error term in the labor decision rule captures the statistical fluctuations in gross margin across stores and time periods. Similarly, the error term in the 
sales regression captures the statistical fluctuation in sales across stores and time periods. It is possible that contemporaneous labor and traffic could be correlated with both errors. For example, price promotions have been found to impact both sales and gross margin in the marketing literature. Since promotions data are unobservable, the errors in those periods could be correlated with traffic. Similarly, if the retailer increases labor in anticipation of promotions then labor could be correlated with the error term as well. To overcome this endogeneity problem, we follow Judge et al. (1985) to use lagged values of labor and traffic as instrument variables. Lagged labor has been used as an instrument variable in retail settings in prior studies as well (Siebert and Zubanov 2010). Specifically, we use labor and traffic that are lagged by 7 days as instruments in our analysis. These serve as appropriate instrument variables since they will be correlated with contemporaneous labor and traffic respectively, but will be uncorrelated with contemporaneous error terms. We also use an alternate instrument variable based on the traffic data of a co-located retailer (Gamma) to separate the exogenous variations in traffic and labor data from the endogenous variation of these variables. Since we have traffic data from the co-located retailer for only 17 of the 41 store locations, we report this analysis as a robustness check in $§ 5.4$.

Based on the population moment conditions, we must have for each store $i$ the sample average of the vector of random variables $Z$,

$$
G_{i}\left(\theta_{i}\right)=\frac{1}{T} \sum_{t=1}^{T} Z_{i t} \varepsilon_{i t}\left(\theta_{i}\right)
$$

as close to zero as possible (where $T=$ total number of individual daily observations for store $i$ ). The GMM estimator determines a parameter vector $\widehat{\theta}_{l}$ that minimizes a quadratic function of this sample average. More specifically, the GMM estimate is the vector $\hat{\theta}_{i}$, which optimizes

$$
\min _{\theta_{i}} G_{i}\left(\theta_{i}\right)^{\prime} A_{i} G_{i}\left(\theta_{i}\right)
$$

where $\mathrm{A}$ is a weighting matrix for the two moments. We use a commonly followed two-step estimation method. In the first step, we use GMM with the pre-specified weighting matrix $A_{1 i}=I$, the identity matrix, that gives an initial estimate, $\hat{\theta}_{1 \mathrm{i}}$, which is also consistent. We use $\hat{\theta}_{1 \mathrm{i}}$ to estimate the asymptotic variance-covariance matrix of the moment conditions:

$$
A_{2 i}=\left(E\left[G_{i}\left(\hat{\theta}_{1 i}\right) G_{i}\left(\hat{\theta}_{1 i}\right)^{\prime}\right]\right)^{-1}
$$

The same GMM procedure is now run a second time with this new weighting matrix to arrive at our parameter estimate, $\hat{\theta}_{2 i}$. The weighting matrix used in the second step also accounts for any heteroskedasticity and autocorrelation effects that might be present in the data. We also explored iterating this process several times (through the iterated GMM framework) and found our estimates to be very similar to that obtained from the two-step estimation method. Hence we report the results from the two step estimation method. 


\subsection{Estimation results}

We estimate the parameters $\alpha_{i}, \beta_{i}, \gamma_{i}, w_{i}$ in the following way. We use average hourly values of sales, traffic and labor for store $i$ on day $t$ in our estimation equations 7 . The summary statistics of the estimation results for the sample across the 41 stores are summarized in Table 2. Individual estimates for each store in the sample are given in appendix A1.

We find that the marginal cost of labor, $w_{i}$, exhibits considerable heterogeneity across the 41 stores. The average, standard deviation, minimum and maximum values of $w_{i}$ are $\$ 58.87, \$ 22.43, \$ 22.46$ and $\$ 115.60$, respectively.

In addition, we find significant differences in the rest of the parameter estimates across weekdays and weekends sample for each store. The average traffic elasticity $\left(\beta_{i}\right)$ for each of the 41 stores, was found to be lower during weekends as compared to weekdays $(p<0.05)$. Similarly, the responsiveness of labor to sales $\left(-\gamma_{i}\right)$ was found to be significantly lower on weekends than on weekdays $(p<0.001)$. Finally, the imputed cost of labor is significantly higher during weekdays than weekends $(p<0.001)$. These results are consistent with anecdotal evidence that there may be a relatively higher number of browsers who tend to visit the stores during weekends as compared to weekdays, and with prior literature on higher usage of lower wage part-time labor on weekends in other retail organizations (Lambert, 2008).

\section{Results}

\subsection{Model Validation}

We validate our model by examining the statistical fit of the model in our data and determining if the parameter estimates are consistent with economic behavior of managers identified in prior research. First, consider the statistical fit of our model. We conduct a goodness-of-fit test for the sales equation (6) and found the adjusted $\mathrm{R}^{2}$ to be $56.2 \%$ and $51.5 \%$ for the weekday and weekend data sets respectively. Second, we conduct out-of-sample goodness-of-fit tests where we exclude data from the last two weeks of every month from our fit sample. The parameters of the sales response model estimated from the fit sample are used to generate sales predictions for the test sample. The correlation between predicted sales and actual sales were $62.9 \%$ and $60.1 \%$ for the weekday and weekend samples, respectively. Both these tests indicate that the sales model we use can capture majority of the variation in our sample. Note that we did not repeat a similar analysis for profit model since we do not possess profit data.

Next, we want to determine if the economic behavior implied by the imputed cost parameter is consistent with prior research as this would build confidence in our model specification. On the contrary, if the behavior implied by imputed cost parameter contradicts prior research, then either our model specification or our underlying assumptions about managerial behavior could be incorrect. To do this, we examine if the findings of Campbell and Frei (2010) hold in our setting as well. Campbell and Frei (2010) find that operating managers take local market characteristics into account when deciding on the number 
of tellers to schedule in a retail banking setting. They identify the cost that customers place on high service time to be one such local market characteristic and show competition and median household income to be suitable proxies for this cost. Similar examples of managers placing lower emphasis on cost while placing higher emphasis on service level have also been found in other settings (Png and Reitman, 1994; Ren and Willems, 2009). We test if the imputed cost of labor for different store managers also exhibit similar behavior. We use the number of women's clothing stores as a proxy for competition $\left(\mathrm{Comp}_{i}\right)$ and median household income $\left(H H I_{i}\right)$ as a proxy for high value that customers place on waiting time in the area. In addition, labor cost is dependent on the demand for labor. Hence, we include the number of local clothing stores $\left(\right.$ Stores $_{i}$ ) as a proxy for employment opportunities in the area. Since sales associates' skills may be fairly generic so that other types of stores may increase demand for the associates' labor as well, we repeat our analysis with the total number of retail stores as a proxy for employment opportunities and find no qualitative difference in our results. Finally, we use average store sales volume to control for store size. We run a cross-sectional regression where for each store $i$,

$$
w_{i}=\alpha_{0}{ }^{w}+\alpha_{1}{ }^{w} \text { Store }_{i}+\alpha_{2}{ }^{w} \text { Comp }_{i}+\alpha_{3}{ }^{w} \text { HHI }_{i}+\alpha_{4}{ }^{w} \text { Store_Sales }_{i}+\varepsilon_{i}{ }^{w}
$$

Table 3 displays results of this regression. In line with our expectations, we find that a higher imputed cost is negatively associated with higher values of household income and competition, i.e., $\alpha_{2}{ }^{w}<0$ and $\alpha_{3}{ }^{w}<0$, and is positively and significantly related to higher opportunities for employment, i.e., $\alpha_{1}{ }^{w}>0$ (significant at $p<0.05$ ).

As a robustness test, we use the number of direct competitors present in the same mall as the stores in our sample as a measure of competition. This list of direct competitors was obtained from Hoover's company analysis reports accessible through Lexis-Nexis Academic website. We use the store location information available from the individual retailer websites to determine if the competitor was present in the same mall as the stores in the sample. We find qualitatively similar results when we use this alternate measure of competition as well. Thus, our results suggest that store managers take local market characteristics into account when determining the amount of labor required in their stores, in line with prior literature.

To summarize, tests of statistical fit as well as economic behavior implied by the imputed cost parameters indicate that our underlying model is valid. Having validated our model, we next examine the extent of understaffing in each of the 41 stores in our sample.

\subsection{Extent of Understaffing at the hourly level}

We determine the extent of understaffing at the hourly level in the following way. First, we use equation 5 to compute the optimal labor plan for each hour, for the entire sample, using parameter estimates obtained earlier. The difference between the actual labor and this optimal labor will give us the theoretical upper bound of the extent of understaffing and overstaffing in the stores for the following 
reason. At the hourly level, we expect actual labor to deviate from optimal labor due to several constraints that the manager needs to consider when scheduling labor. For example, Quan (2004) states that retailers need to account for different factors such as minimum staffing requirements, schedule fairness, distribution of skills, and government and union requirements such as maximum shifts per day, seniority, and employee quality of life considerations. However, it is difficult to take all these constraints into account in the existing profit maximization model as we do not have information on the individual constraints faced by each store manager. Thus, our optimal labor plan is based on the solution to the unconstrained profit maximization problem represented in equation 5. The estimate of lost sales due to understaffing and resulting improvement in profitability from having optimal labor in the store would thus indicate the maximum possible improvement that would be achieved in these stores ${ }^{3}$.

We compute the deviation of actual labor from the optimal labor plan (i.e. $\Delta l_{i t h}=l_{i t h}^{*}-l_{i t h}$ ) for each hour. Positive deviations indicate understaffing, while negative deviations would indicate overstaffing relative to the optimal labor plan. Recall that our parameters were estimated at the daily level. Therefore, an alternate approach would be to estimate the parameters using hourly data. We do this analysis as robustness check in $\S 5.4$.

Deviations at the hourly level help us understand if stores are systematically understaffed or overstaffed for certain hours of the day. These deviations are computed as average deviation for a given hour across different days for each store. For each store $i$ let $t$ represent a day and $h$ represent an operating hour, $i=1 \ldots \ldots 41, t=1 \ldots . \mathrm{T}$ ( $\mathrm{T}=190$ for weekdays and 143 for weekends), and $h=1 \ldots \ldots \mathrm{H}$ ( $\mathrm{H}=$ total operating hours). The average hourly deviation for store $i$ in hour $h$ is $\Delta l_{i h}=\left\{\sum_{t=1}^{T}\left(\Delta l_{i t h}\right)\right\} / T$.

We have 7790 total store-days (190 days at each of 41 stores) in our weekdays test sample and 5863 total store-days (143 days at each of 41 stores) in our weekend test sample. We describe results here for the weekdays but find qualitatively similar results for weekends as well. These results are presented in Table 4. There are 73800 total store-hours for weekdays. We find that stores appear to be understaffed for $32.88 \%$ of the time. When understaffing occurs, the magnitude of understaffing is 3.22 labor-hour. In other words, the stores were short by 3.22 persons per hour when there was understaffing. This level of understaffing represents a $31.55 \%$ shortage compared to the optimal labor.

Next we examine the extent of overstaffing in the stores. Since stores need to maintain minimum labor in their stores even if there was no traffic, we first calculate the minimum labor for each of the stores and found it to be 1 person per hour. If the model-predicted optimal labor was less than 1 person per hour then we set the optimal labor for that hour to be 1 person. We consider a store to be overstaffed

\footnotetext{
${ }^{3}$ Even though our estimates of lost sales and improvement in profitability are theoretical upper bounds, retailers find it valuable to quantify this magnitude so they might consider alternate actions to relax some of these constraints or work around them, as discussed in the case of retailer Beta in $\S 6$.
} 
during a time period if the actual labor in the store was greater than the optimal labor. The extent of overstaffing in an hour is calculated as the difference between actual labor and the optimal labor. We find that stores were overstaffed for $52.85 \%$ of the time. We determine the magnitude of overstaffing to be 1.02 labor-hour, which represents a staffing level that is more than $24.23 \%$ of the optimal labor. The magnitude of understaffing and overstaffing for each individual store is given in Appendix A2.

Our results show that the stores are understaffed for far fewer hours of the day compared to the periods when they were overstaffed. However, the magnitude of understaffing, when it occurs, is higher than that of overstaffing. Further investigation of the data reveals that only 3 out of the 10 hours of daily operation account for most of the understaffing in a store. We find that over $60 \%$ of the daily traffic arrives during this 3-hour window so we call it the peak hours for a store. Some retailers also call it the power hours for a store. To statistically validate our finding, we run a logistic regression and find statistical support that peak hours are understaffed $(p<0.05)$. Figure 3 shows the plot of actual and optimal labor during peak and non-peak hours to depict the widespread prevalence of understaffing during peak hours.

To triangulate our findings around understaffing, we compare the conversion rate of each store during those hours of weekdays (weekends) that our model identifies as being understaffed to the conversion rate of similar hours of weekdays (weekends) when there is no understaffing. Our expectation is that if our model is able to accurately identify hours when there is understaffing then the conversion rate during those hours should be lower, since labor was found to be positively associated with conversion rate (Perdikaki et al. 2012). Alternatively, it is possible that conversion rate may not decline during understaffed hours if the staff exerts greater effort to compensate for the lack of workers (Kc and Terwiesch 2009). We note that the conversion rate metric is based on number of transactions, a measure that is not part of our model, thus assuring the independence of the metric and the model. We observe a decline of $2.6 \%$ in conversion rate when the stores are understaffed during peak hours in weekdays. During weekends we determine the decline in conversion rate to be $2.9 \%$. These results add validity to our approach for identifying understaffing situations accurately.

\subsection{Impact of understaffing on lost sales and store profitability}

In this section, we measure the impact of understaffing and overstaffing on lost sales and profitability. First, we calculate the sales lift for each store $i$ in each time period (day $t$ and hour $h$ ) that our model identifies the store to be understaffed as shown below:

$$
S_{i t h}^{o}=\widehat{\alpha}_{\imath} \hat{\alpha}_{i d}{ }^{a_{d}} \hat{\alpha}_{i m}{ }^{a_{m}} N_{i t h} \widehat{\beta}_{i} e^{-\widehat{\gamma}_{i} / l_{i t h}^{*}}
$$

Here $l_{i t h}^{*}$ is the optimal labor plan that was generated as explained in the previous section and $S_{i t h}^{o}$ is the sales generated using the optimal labor plan. The difference between sales from the optimal labor plan 
$\left(S_{i t h}^{o}\right)$ and actual sales represents the estimate of lost sales. We divide the lost sales by actual sales to normalize sales across different time periods.

Next, we use the imputed cost $w_{i}$ to compute optimal profit as:

$$
\pi_{i t h}^{o}=S_{i t h}^{o}-\widehat{w}_{i} * l_{i t h}^{*}
$$

Since actual profit data are not available at the hourly level, we substitute actual sales and actual labor in equation 10 to compute the actual profits. The difference between optimal profit and actual profit represent the improvement in store profitability from using an optimal labor plan. We normalize profit improvement by dividing it with actual profits.

First, consider the impact of understaffing on lost sales. The results are presented in Table 5. We determine the lost sales for the 41 stores to be $6.15 \%$. We find that the lost sales during the 3-hour peak period to be $6.33 \%$. Increasing staffing during these periods would reduce lost sales but also increase costs. So, we consider the impact of optimal labor plan on profitability next. We find that following the optimal labor plan would result in an increase in profitability by $5.74 \%$. Even though we observe an increase in profitability during peak and non-peak hours, we believe that the improvement in profitability during peak hours to be more significant. This is because understaffing during non-peak hours is driven by traffic fluctuations and occurs across different hours of the day. Hence it might be harder for managers to address the understaffing during non-peak hours.

On the other hand, reduction in labor during overstaffed hours would lead to a decline in sales and an increase in profitability. We determine the decline in sales to be $3.4 \%$ and the increase in profitability to be $2.04 \%$. The comparable numbers for the weekend sample are $3.1 \%$ and $1.9 \%$ respectively. Thus we find that reduction in understaffing can lead to greater improvements in profitability compared to reduction in overstaffing for this retailer.

We note that our results may be underestimating the true impact of understaffing in retail stores as we do not consider the long-term impact of lost sales on store performance. Customers who did not receive proper service might switch to competitors resulting in a loss of life-time value from those customers (Heskett et al. 1994). For the same reason, managers need to tread the path of reducing labor during overstaffed hours carefully. Even though our results show that reducing overstaffing in the stores could lead to an increase in short-term profitability, the long-term impact of the increase in lost sales due to labor reduction in unclear. Thus we conclude that our results around understaffing are conservative while that around overstaffing require further analysis with long-term customer satisfaction data.

\subsection{Robustness Checks}

We perform a number of robustness checks of our results. First, we rerun our analysis by estimating the parameters of our sales function at the hourly level. Recall that the main results were reported based on parameters estimated with daily data. We find that the parameter estimates at the hourly level are 
largely similar as shown in Table A3 in Appendix. Nevertheless, we compute the lost sales and loss in profitability due to understaffing with these new estimates. We obtain similar results as reported §5.3. For example, we find that the impact of understaffing observed during peak hours on lost sales and profitability to be $5.43 \%$ and $4.9 \%$ respectively.

Second, we perform a more conservative test of our analysis by using a forecast of traffic instead of actual traffic. We do so because store managers would typically use a forecast of traffic in labor planning decisions. Additionally, we divide our sample in to fit and test sample so that we may estimate the impact of understaffing and overstaffing in the test sample using parameter estimates from the fit sample. We find our results to be similar. For example the impact of understaffing observed during peak hours on lost sales and profitability with a one-week ahead forecast of traffic was found to be $4.09 \%$ and $3.31 \%$ respectively.

Third, we use traffic data from a co-located retailer, Gamma, to estimate our moment conditions. Gamma is a family clothing store and belongs to the same industry sub-segment as Alpha (NAICS 448 clothing and clothing accessories stores). Unlike Alpha where we possess hourly data on traffic and labor, we only have daily traffic data for Gamma. We determined that 17 stores of Gamma were co-located in the same mall as Alpha. Hence, we concentrate on these 17 stores. The average correlation between the daily traffic data at the co-located Gamma stores and Alpha stores was 51.34\% in our sample. Hence we replace the 7 day lagged daily labor data of Alpha with contemporaneous average daily traffic data from Gamma stores as instruments in equation 7. We obtain similar results as earlier. For example we find the impact of understaffing observed during peak hours on lost sales and profitability to be $4.32 \%$ and $3.56 \%$ respectively. The range of lost sales estimate in these 17 stores is $1.49 \%$ to $7.15 \%$ and the range of improvement in profitability is $1.03 \%$ to $6.08 \%$.

\section{Pilot Implementation}

Next we demonstrate the managerial contribution of our approach through a pilot implementation at another retailer, Beta. Beta is a large specialty retailer with over 100 stores in the United States and Canada. The annual revenue for Beta exceeds 1 billion USD. Beta's stores vary in size but each was larger than 10,000 sq. ft. Beta had recently installed traffic counters in its stores and was using traffic data to determine sales productivity in its stores. At the time of our pilot implementation, Beta was contemplating purchase of labor planning software to improve their staffing decisions and contacted us to identify any understaffing in their stores.

There were a number of similarities between the store managers of Alpha and those of Beta. In both cases, store managers were responsible for making labor decisions and the store managers' compensation was based on salary as well as bonuses that were tied to store profits. Customer satisfaction metrics were not considered in the performance appraisal of store managers. 
We followed an iterative cycle of model validation and analysis to identify understaffing at Beta's stores and estimate its impact on lost sales. This test-and-learn approach to the decision-making process has been advocated in literature to ensure that the model provides reliable insights for managers to take appropriate actions (Davenport, 2009). For our preliminary analysis we obtained data on hourly sales, traffic, and labor for 4 stores in the United States and Canada. We supplemented these data with field trips to 3 of their stores and several hours of telephone conversations with their store managers, district managers, and several managers at the corporate headquarters. These conversations revealed that our model from Alpha could reasonably capture the decision making process of store managers in Beta.

Next, we went through a model validation process, i.e. we tested if the model could accurately capture the underlying relationships between store sales, traffic and labor for Beta. Our conversations revealed that a managerial intervention had occurred in one of their stores on a staffing issue. We use this intervention as a natural experiment to test the validity of our model. In May 2011, one of the Canadian stores was asked to reduce their staffing level as it was deemed to be overstaffed. This determination was based on the ratio of payroll to sales for this store which was higher than that of comparable stores. Our follow-up calls with the store manager of this Canadian store revealed that his store became overstaffed as the store was protecting many sales associates from losing their jobs though their sales became weak after January 2011. Once the managerial intervention occurred, this store gradually reduced its workforce by not replacing associates who were lost in attrition. Based on our discussions, we posited that this store manager's imputed cost of labor should have increased after the intervention in May 2011. We also expect that the level of overstaffing should have reduced from May 2011. We examine if our model is able to detect both these changes. We obtained hourly data on traffic, sales, and labor during the period February-July 2011 for this store. The average hourly sales, traffic and labor for this store was \$2309.42, 44.02 and 8.54 labor-hour respectively. Then we split the sample into February-April time frame and May-July timeframe to capture the periods before and after the managerial intervention in this Canadian store. We follow the same methodology as described earlier for Alpha to impute labor costs in these two subsamples and quantify the extent of understaffing and overstaffing for different hours of the day.

Consistent with our expectations, we find that the imputed cost of labor increased from $\$ 103.25$ to $\$ 147.16^{4}$ suggesting that the store manager was placing greater emphasis on labor costs. Further, we find that the extent of overstaffing was also reduced. Earlier, the store was overstaffed for $78.56 \%$ of the hours during the time period February-April 2011 but the extent of overstaffing declined to $41.16 \%$ during May-July 2011. Since both results are consistent with prior expectations, they offer further proof of our model validity.

\footnotetext{
${ }^{4}$ Recall that these costs are not directly comparable to wages since these costs are normalized by store gross margin.
} 
In addition to the above results, we obtained the following unexpected insight for this store. Figures $4 \mathrm{a}$ and $4 \mathrm{~b}$ presents the traffic flow for different hours of the day during February-April and May-July, respectively. We notice that the traffic has two spikes. The first occurs between 12-3PM and another smaller spike occurs between 4-5PM in February-April. The smaller spike shifts to 7-8PM during MayJuly as shown in Figure 4b. Our analysis reveals that the store is understaffed during 12-3PM for the entire duration but the store is not understaffed between 4-5PM during February-April or May-July timeframes. However, the shift in traffic caused the store to become understaffed during 7-8PM in MayJuly as the store did not adjust its labor plan. Consistent with our model predictions of understaffing during 7-8PM, we find that the conversion rate declined by $3 \%$ during this hour when the store was understaffed compared to when it was not. Our follow-up discussions with this store manager revealed that the traffic pattern shifts in May-July due to warmer weather in Canada. However, the store manager had not taken any specific action to change the labor plan to match the shift in traffic pattern.

Our analysis of the rest of the stores revealed understaffing during peak hours in all of them. We also observed a 3-5\% decline in conversion rate during peak hours when the stores were understaffed. Interestingly, we found that the level of understaffing in one of the stores was twice on Mondays compared to the rest of the days. We discussed our findings with the store manager to understand if there were any underlying operational constraints that might lead to this systematic understaffing. We found that while the normal practice was to have store associates start their shifts at different times of the day so that not all store associates take their lunch breaks at that same time, on Mondays, there was an "allhands-on-deck" meeting in the morning that requires all the store associates to be present. As a result, majority of the store associates started their shift on Mondays at the same time that in-turn lead to a common lunch-break time for most of the sales associates. The high level of peak-hour understaffing that we observed on Mondays in this store was a result of this staffing issue.

As we indicated earlier, understaffing and overstaffing occur in retail stores due to schedule inflexibility and forecast errors. To address these issues, this retailer is considering three different strategies that could improve its staffing flexibility. First, the retailer intends to examine the efficacy of straddling shifts of full-time workers so that there is sufficient coverage during peak hours. A large body of academic literature has developed mixed integer linear programming techniques to schedule full-time workers to minimize labor hours while satisfying variable workforce requirements of a service delivery system (example, Dantzig 1954, Morris and Showalter 1983). Second, this retailer believes that crosstraining of backroom workers could help alleviate the understaffing problem in the sales floor during peak hours. Cross-training workers to increase flexibility have been well established in the manufacturing arena (Fryer 1974; Daniels et al. 2004). Finally, this retailer is also considering scheduling part-time workers during the peak hours while respecting the minimum shift lengths for these workers. In order to 
test which strategy (or hybrid of strategies) might work, the retailer is planning to conduct experiments in its stores to determine their impacts on conversion rate and profitability.

To summarize, our analysis of Beta's data yields the following insights. First, we provide additional evidence of external validity of our model by using a natural experiment at this retailer. Second, we find our result that retail stores are understaffed during peak hours to be robust across retailers. Third, we demonstrate the managerial contribution of our approach to identify and quantify the impact of understaffing using a pilot implementation. Our conservative estimate of lost sales for these 4 stores on average was about $\$ 240,000$ per year, which was roughly $2.5 \%$ of their annual sales. One senior manager commented that, "We always knew our stores were understaffed at some times and overstaffed during others. Culturally we have tended to nod at this issue but this analysis shows how we have undervalued the impact of understaffing on financial performance."

\section{Limitations and Conclusion}

This paper contributes to a growing literature on the use of business analytics in providing actionable insights and decision support based on micro-level data by providing an approach that leverages detailed customer traffic, store transactional data, and labor data to identify periods of understaffing and overstaffing in retail stores.

Second, we add to the literature that studies the impact of labor on retail store performance (Fisher et al. 2007; Ton and Huckman 2008; Netessine et al. 2010; Ton 2009; Perdikaki et al. 2012) by quantifying the impact of understaffing and overstaffing on lost sales and profitability. Our results indicate the stores are typically understaffed for fewer hours in a day compared to being overstaffed. Yet, the impact of understaffing on profitability is much higher than that of overstaffing.

Third, we contribute to the small but growing literature that empirically analyses the heterogeneity in managerial decisions across different local markets (Ren and Willems 2009, von Donselaar et al. 2010, Campbell and Frei 2010). Our paper extends the findings of Campbell and Frei (2010) from banking to retail sector.

Finally, our paper documents the implementation of our decision support tool at a retailer that helps the retailer identify time periods when a store is overstaffed and understaffed, and quantifies the impact of understaffing on lost sales for the retailer. By developing the decision support tool with data from one retailer and implementing it at another retailer, our study demonstrates the external validity of our approach and the managerial significance of our results.

One limitation of our study is that it is focused on short-term profitability. Prior research has shown that decrease in service quality could result in a decline in customer satisfaction and loyalty (Zeithaml et al. 1996). Therefore, the impact of understaffing on total profitability could be much higher than what we 
estimate it to be. Future research can use longer time series of data for each store and study the impact of understaffing on future profitability.

Finally, we did not possess data on proportion of full-time workers, part-time workers, and temporary workers. Because part-time workers and temporary workers may not have the same amount of cumulative experience as full-time workers, they would possess lower knowledge (Argote 1999) and likely provide lower quality of service. Thus, future research may examine if the impact of understaffing on store profitability varies across types of labor.

\section{References}

Allon G, A. Federgruen. M. Pierson. 2011. How Much Is a Reduction of Your Customers' Wait Worth? An Empirical Study of the Fast-Food Drive-Thru Industry Based on Structural Estimation Methods. Manufacturing \& Service Operations Management. 9(4), 518-534.

Argote, L. 1999. Organizational Learning: Creating, Retaining and Transferring Knowledge. Kluwer, New York.

Bureau of Labor Statistics. March 2009. Holiday Season Hiring in Retail Trade

Cohen, M.A., T.H. Ho, J.Z. Ren, C. Terwiesch. 2003. Measuring imputed cost in the semiconductor equipment supply chain. Management Science. 49(12), 1653-1670.

Cooper, R., R.S. Kaplan. 1988. Measure Costs Right: Make the Right Decisions. Harvard Business Review. 66(5), 96-103.

Daniels, R.L., J.B. Mazzolla, D. Shi. 2004. Flow shop scheduling with partial resource flexibility. Management Science. 50(5), 658-669.

Dantzig, G. 1954. A Comment on Edie's Traffic Delay at Toll Booths. Operations Research. 2(3), 339341.

Davenport, T. 2009. How to Design Smart Business Experiments. Harvard Business Review. 87(2), 68-

76.

DeHoratius, N., A. Raman. 2007. Store manager incentive design and retail performance: An exploratory investigation. Manufacturing \& Service Operations Management. 9(4), 518-534.

Fisher, M.L., J. Krishnan, S. Netessine. 2007. Retail store execution: An empirical study. Working paper, University of Pennsylvania, Philadelphia, PA.

Fisher, M.L., A. Raman. 2010. The New Science of Retailing, Harvard Business Press.

Fryer, J.S. 1974. Effects of Shop Size and Labor Flexibility in Labor Production System. Management Science. 21(5), 507-515.

Gans, N., Koole, G., Mandelbaum, A. 2003. Telephone call centers: Tutorial, review and research prospects. Manufacturing and Service Operations Management 5(2), 79-141. 
Green L. V. 2004. In Operations Research and Health Care: A Handbook of Methods and Applications, Capacity planning and management in hospitals, eds Brandeau M. L., Sainfort F., Pierskalla W. P. (Kluwer Academic Publishers, Norwell, MA), 15-42.

Grewal, D., J. Baker, M. Levy, G.B. Voss. 2003. The effects of wait expectation and store atmosphere evaluations on patronage intentions in service-intensive retail stores. Journal of Retailing. 79(4), 259268.

Hann, I., and C. Terwiesch. 2003. Measuring the Frictional Costs of Online Transactions: The Care of a Name-Your-Own-Price Channel. Management Science. 49(11), 1563-1579.

He, B., F. Dexter, A. Macario, S. Zenios. 2012. The Timing of Staffing Decisions in Hospital Operating Rooms: Incorporating Workload Heterogeneity into the Newsvendor Problem. Manufacturing \& Service Operations Management. 14(1), 99-114.

Heskett, J.L., T.O. Jones, G.W. Loveman, W.E. Jr Sasser, L.A. Schlesinger. 1994. Putting the service profit chain to work. Harvard Business Review. 72(2), 164-174.

Hogarth, R.M., S. Makridakis. 1981. Forecasting and Planning: An Evaluation. Management Science. 27(2), 115-138.

Hopp, W.J., S.M.R. Iravani, G.Y. Yuen. 2007. Operations systems with discretionary task completion. Management Science. 53(1), 61-77.

Holt, C. C., F. Modigliani, H. A. Simon. 1956. Linear decision rule for production and employment scheduling. Management Science. 2(2), 159-177.

Horsky, D. and P. Nelson. 1996. Evaluation of Salesforce Size and Productivity Through Efficient Frontier Benchmarking. Marketing Science. 15(4), 301-320.

Judge, G.G., W.E. Griffiths, R.C. Hill, H. Lutkepohl, T.H. Lee. 1985. The theory and practice of econometrics, $2^{\text {nd }}$ ed. Wiley, New York.

Kahneman, D., D. Lovallo. 1993. Timid choices and Bold Forecasts. Management Science. 39 (1), 17-31.

Kc, D. S., C. Terwiesch. 2009. Impact of Workload on Service Time and Patient Safety: An Econometric Analysis of Hospital Operations. Management science. 55(9), 1486-1498.

Lam, S.Y, M. Vandenbosch, M. Pearce. 1998. Retails sales force scheduling based on store traffic forecasting. Journal of Retailing. 74(1), 61-88.

Lambert, S. 2008. Passing the buck: Labor flexibility practices that transfer risk onto hourly workers. Human Relations. 61(9), 1203-1227.

Liu, Y., S. Ram, R.F. Lusch, M. Brusco. 2010. Multicriterion Market Segmentation: A New Model, Implementation, and Evaluation. Marketing Science. 29(5), 880-894.

Loveman. G. 1998. Employee, satisfaction, customer loyalty, and financial performance: An empirical examination of the service profit chain in retail banking. Journal of Service Research. 1(1), 18-31. 
Lu, Y, M. Olivares, A. Musalem, A. Schilkurt. 2011. Measuring the effect of queues on customer purchases. Working paper. Columbia University.

Maxham, J.G. III, R.G. Netemeyer, D.R. Lichenstein. 2008. The Retail Value Chain: Linking Employee Perceptions to Employee Performance, Customer Evaluations, and Store Performance. Marketing Science. 27(2), $147-167$.

Morris, J., M. Showalter. 1983. Simple Approaches to Shift, Days-off and Tour Scheduling Problems. Management Science. 29(8), 942-950.

Musalem, A., M. Olivares, C. Terwiesch, E.T. Bardlow, D. Corsten. 2010. Structural Estimation of Effect of Out-of-Stocks. Management Science. 56(7), 1180-1197.

Netessine, S., M. L. Fisher, J.Krishnan. 2010. Labor Planning, Execution, and Retail Store Performance: an Exploratory Investigation, Working Paper, The Wharton School, University of Pennsylvania.

Olivares, M., C. Terwiesch, L. Cassorla. 2008. Structural Estimation of the Newsvendor Model: An Application to Reserving Operating Room Time. Management Science. 14(1), 145-162.

Park, Y, C.H. Park, V. Gaur. 2010. Consumer Learning, Word of Mouth, and Quality Competition. Working Paper, The Johnson School, Cornell University.

Perdikaki, O., S Kesavan, and J.M. Swaminathan. 2012. Effect of retail store traffic on conversion rate and sales. Manufacturing and Service Operations Management. 5(2), 79-141.

Png, I.P.L., D. Reitman. 1994. Service time competition. The RAND Journal of Economics. 25(4), 619634.

Quan, V. 2004. Retail Labor Scheduling. OR/MS Today, December 2004.

Reiss, P., and Wolak, F. 2007. Structural Econometric Modeling: Rationales and Examples from Industrial Organization. Heckman J., and Leamer, E. (eds.), Handbook of Econometrics, Chapter 64, 6. Part A. 4277-4415. Amsterdam: North-Holland.

Ren, J., S. Willems, 2009. An empirical study of inventory policy choice and inventory level decisions. Working paper, Boston University, Boston.

Ruiz, J.P., J.C. Chebat, P. Hansen. 2004. Another trip to the mall: a segmentation of customers based on their activities. Journal of Retailing and Consumer Services. 11(6), 333-350.

Siebert, W.S., N. Zubanov. 2010. Management economics in a large retail company. Management Sci. 56(8), 1398-1414.

Stiglitz, J. 1974. Alternative Theories of Wage Determination and Unemployment in L.D.C.'s: The Labor Turnover Model. Quarterly Journal of Economics. 88(2), 194-227.

Thomadsen, R. 2005. The Effect of Ownership Structure on Prices in Geographically Differentiated Industries. The RAND Journal of Economics. 36(4), 908 - 929. 
Ton, Z. and R.S. Huckman. 2008. Managing the impact of employee turnover on performance: The role of process conformance. Organization Science. 19(1), 56-58.

Ton, Z. 2009. The effect of labor on profitability: The role of quality. Working Paper, Harvard Business School.

Tziner A., A. Birati. 1996. Assessing employee turnover costs: A revised approach. Human Resource Management Review. 6(2), 113-122.

von Donselaar, K.H, V. Gaur, T. van Woensel, R.A.C.M. Broekmeulen and J.C. Fransoo. 2010. Ordering Behavior in Retail Stores and Implications for Automated Replenishment. Management Science. 56(5), 766-784.

Wooldridge, J. M., Econometric Analysis of Cross Section and Panel Data. Cambridge, MA: MIT Press

Zeithaml, V.A., L.L. Berry, A. Parasuraman. 1996. The Behavioral Consequences of Service Quality. Journal of Marketing. 60(2), 31-46.

\section{Figures and Tables:}

Figure 1: Labor planning process
Sales/Traffic
Forecast
Planned hours
Scheduled hours

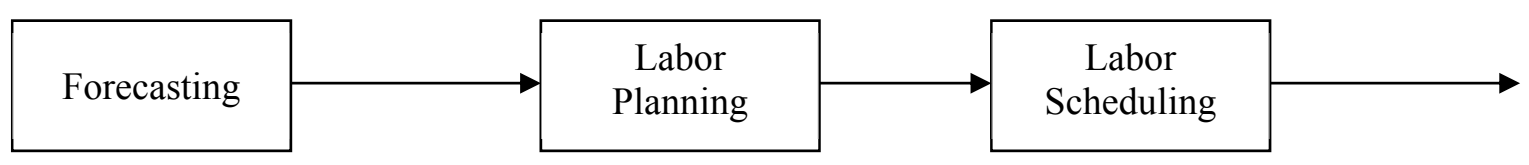

Figure 2: Cluster analysis of average traffic across days of week and months of year
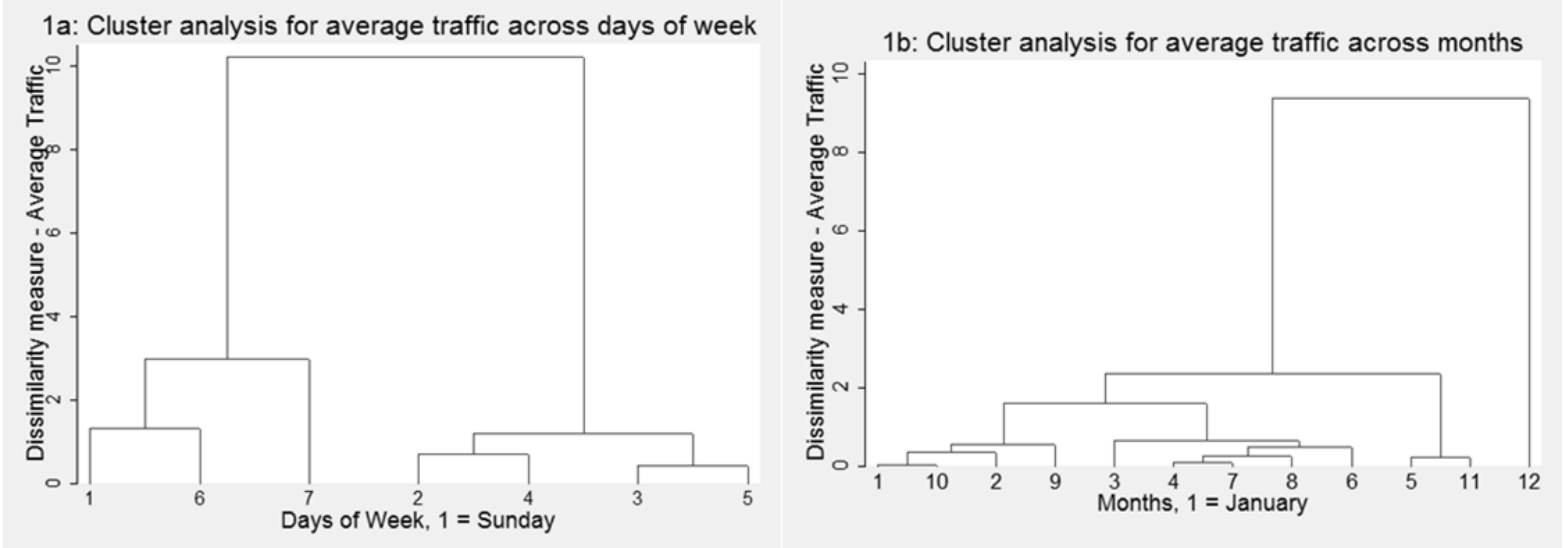
Figure 3: Comparison of actual labor and optimal labor for stores during peak and non-peak hours
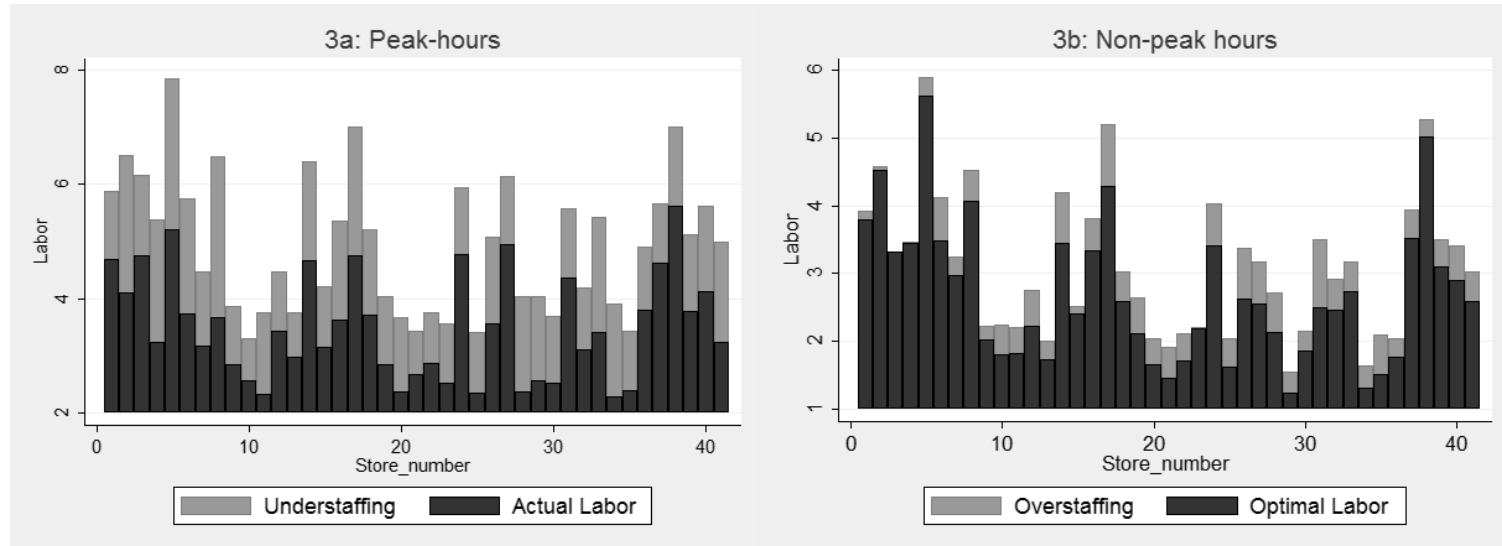

Figure 4: Traffic patterns for Feb-Apr and May-Jul for Beta

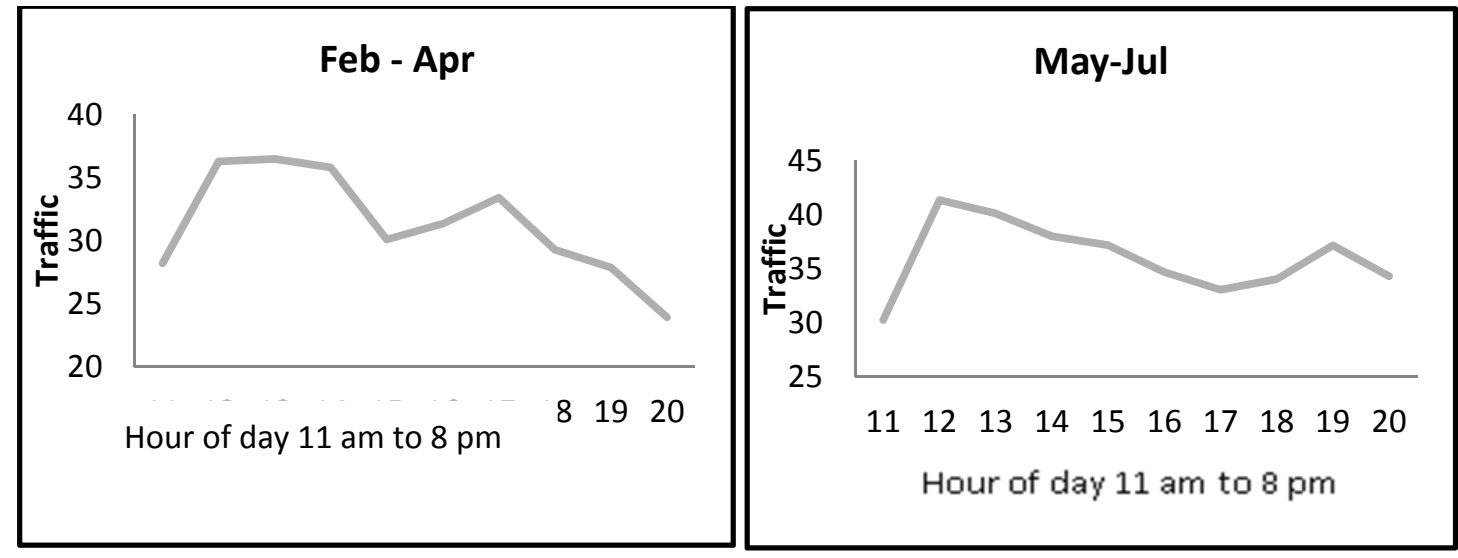

Table 1a: Store variable names, definitions and summary statistics

\begin{tabular}{ccccccccc}
\hline Name & \multicolumn{4}{c}{ Weekdays } & \multicolumn{5}{c}{ Weekends } \\
\hline $\begin{array}{c}\text { Store_ } \\
\begin{array}{c}\text { Sales } \\
\text { ith }\end{array}\end{array}$ & Avg. & Std. dev & Min & Max & Avg. & Std. dev & Min & Max \\
$\begin{array}{c}\text { Actual_- } \\
\text { Labor }_{\text {ith }}\end{array}$ & 5.41 & 2.11 & 1.0 & 16.0 & 10.27 & 2.84 & 2.0 & 32.0 \\
$\quad \begin{array}{c}\text { Trans- } \\
\text { actions }_{\text {ith }}\end{array}$ & 7.14 & 4.59 & 1.0 & 46.0 & 11.71 & 7.08 & 1.0 & 72.0 \\
Traffic $_{\text {ith }}$ & 48.99 & 29.31 & 5.0 & 437.0 & 95.51 & 56.40 & 17.0 & 630.0 \\
CR $_{\text {ith }}$ & 16.79 & 2.43 & 9.40 & 20.19 & 13.38 & 4.14 & 1.85 & 25.89 \\
BV $_{\text {ith }}$ & 90.93 & 42.42 & 10.31 & 1371.26 & 94.58 & 50.11 & 15.50 & 1448.56 \\
\hline
\end{tabular}


Table 1b: Demographic variable names, definitions and summary statistics

\begin{tabular}{rlcccc}
\hline Name & \multicolumn{1}{c}{ Definition } & Average & Std Dev & Min & Max \\
\hline Stores & $\begin{array}{c}\text { Number of clothing stores in } \\
\text { the zip code scaled by } \\
\text { population (in thousands) } \\
\text { Median House Household } \\
H H I_{i}\end{array}$ & .064 & .056 & .001 & .207 \\
& $\begin{array}{c}\text { Income for the zip code scaled } \\
\text { by population(in thousands) } \\
\text { Number of competing retailers } \\
\text { in the zip code scaled by } \\
\text { population (in thousands) }\end{array}$ & 65.15 & 31.641 & 31.510 & 212.989 \\
\hline
\end{tabular}

Table 2: Estimation results

\begin{tabular}{ccccccccc}
\hline & \multicolumn{4}{c}{ Weekdays } & \multicolumn{4}{c}{ Weekends } \\
\hline Parameter & Average & Std Dev & Min & Max & Average & Std Dev & Min & Max \\
$\boldsymbol{\alpha}_{\boldsymbol{i}}$ & 16.11 & 3.67 & 11.06 & 22.69 & 20.88 & 4.41 & 13.11 & 27.19 \\
$\boldsymbol{\beta}_{\boldsymbol{i}}$ & 0.26 & 0.08 & 0.15 & 0.37 & 0.19 & 0.06 & 0.12 & 0.31 \\
$\boldsymbol{\gamma}_{\boldsymbol{i}}$ & 12.54 & 3.45 & 7.01 & 19.88 & 18.60 & 4.58 & 12.32 & 27.02 \\
$\boldsymbol{w}_{\boldsymbol{i}}(\$ / \boldsymbol{h r})$ & 58.87 & 22.43 & 22.46 & 115.60 & 38.07 & 15.22 & 19.32 & 80.66 \\
\hline
\end{tabular}

Table 3: Regression of imputed cost of labor on local market area characteristics

\begin{tabular}{|c|c|c|}
\hline & Weekdays & Weekends \\
\hline Intercept & $\begin{array}{c}29.857^{* * *} \\
(6.82)\end{array}$ & $\begin{array}{c}25.626^{* * *} \\
(3.056)\end{array}$ \\
\hline Stores $_{i}$ & $\begin{array}{c}346.80^{* * *} \\
(53.12)\end{array}$ & $\begin{array}{c}281.24^{* * *} \\
(23.34)\end{array}$ \\
\hline $\operatorname{Comp}_{i}$ & $\begin{array}{c}-107.93^{* * *} \\
(28.827)\end{array}$ & $\begin{array}{c}-131.842^{* * *} \\
(17.21)\end{array}$ \\
\hline$H H I_{i}$ & $\begin{array}{l}-.109^{* *} \\
(.035)\end{array}$ & $\begin{array}{c}-.105^{* *} \\
(.037)\end{array}$ \\
\hline Store_Sales $_{i}$ & $\begin{array}{c}.005 \\
(.014)\end{array}$ & $\begin{array}{c}0.003 \\
(0.007)\end{array}$ \\
\hline$\underset{\mathrm{n}}{\text { Adjusted } \mathrm{R}^{2}}$ & $\begin{array}{c}0.31 \\
41\end{array}$ & $\begin{array}{c}0.28 \\
41\end{array}$ \\
\hline
\end{tabular}


Table 4: Extent of understaffing and overstaffing

\begin{tabular}{|c|c|c|c|}
\hline Variable & Measure & Weekdays & Weekends \\
\hline \multirow{3}{*}{$\begin{array}{l}\text { Total understaffing } \\
\text { (across all hours) }\end{array}$} & $\begin{array}{c}\text { Understaffing (\% of } \\
\text { time) }\end{array}$ & $32.88 \%$ & $48.65 \%$ \\
\hline & $\begin{array}{l}\text { Understaffing } \\
\text { (magnitude) }\end{array}$ & 3.22 labor-hour & 4.81 labor-hour \\
\hline & $\begin{array}{l}\text { Understaffing (\% of } \\
\text { optimal labor) }^{\mathrm{a}}\end{array}$ & $31.55 \%$ & $27.65 \%$ \\
\hline \multirow{3}{*}{$\begin{array}{l}\text { Understaffing } \\
\text { during peak } \\
\text { hours }\end{array}$} & $\begin{array}{c}\text { Understaffing (\% of } \\
\text { time) }\end{array}$ & $68.21 \%$ & $75.90 \%$ \\
\hline & $\begin{array}{l}\text { Understaffing } \\
\text { (magnitude) }\end{array}$ & 3.52 labor-hour & 5.14 labor-hour \\
\hline & $\begin{array}{c}\text { Understaffing ( } \% \text { of } \\
\text { optimal labor) }\end{array}$ & $36.48 \%$ & $31.85 \%$ \\
\hline \multirow{3}{*}{$\begin{array}{l}\text { Total overstaffing } \\
\text { (across all hours) }\end{array}$} & $\begin{array}{c}\text { Overstaffing (\% of } \\
\text { time) }\end{array}$ & $52.85 \%$ & $46.26 \%$ \\
\hline & $\begin{array}{l}\text { Overstaffing } \\
\text { (magnitude) }\end{array}$ & 1.02 labor-hour & 1.66 labor-hour \\
\hline & $\begin{array}{l}\text { Overstaffing ( } \% \text { of } \\
\text { optimal labor) }\end{array}$ & $24.23 \%$ & $20.69 \%$ \\
\hline
\end{tabular}

${ }^{\mathrm{a}}$ For example if in a given hour the optimal labor is 10.2 labor-hour and understaffing is 3.22 labor-hour, then this represents $31.55 \%$ of the optimal labor for that hour.

Table 5: Impact of understaffing and overstaffing on lost sales and profitability

\begin{tabular}{c|ccc}
\hline Variable & Measure & Weekdays & Weekends \\
\hline $\begin{array}{c}\text { Total understaffing } \\
\text { (across all hours) }\end{array}$ & $\begin{array}{c}\text { Impact on lost sales }^{\mathrm{a}} \\
\text { Impact on } \\
\text { profitability }\end{array}$ & $6.15 \%$ & $5.54 \%$ \\
\hline $\begin{array}{c}\text { Understaffing } \\
\text { during peak } \\
\text { hours }\end{array}$ & $\begin{array}{c}\text { Impact on lost sales } \\
\text { Impact on } \\
\text { profitability }\end{array}$ & $5.74 \%$ & $4.83 \%$ \\
\hline $\begin{array}{c}\text { Total overstaffing } \\
\text { (across all hours) }\end{array}$ & $\begin{array}{c}\text { Impact on lost sales } \\
\text { Impact on } \\
\text { profitability }\end{array}$ & $-3.38 \%$ & $6.12 \%$ \\
\hline
\end{tabular}

${ }^{a}$ Impact on lost sales is calculated as the percentage improvement in sales obtained from having optimal labor (obtained from using coefficient estimates of model 7) over actual sales. ${ }^{\mathrm{b}}$ Impact on profitability is calculated as the percentage improvement in profitability over actual profits. Optimal profit is calculated as the difference between optimal sales (using coefficient estimates of model 7) and cost of labor (using the estimates of imputed cost of labor and optimal labor). The actual profit is calculated as the difference between actual sales and cost of labor (using the estimates of imputed cost of labor and actual labor). ${ }^{c}$ Negative values of sales improvement indicate the amount by which managers would lose sales if they reduced labor during overstaffed hours. 


\section{Appendix}

A1 Individual store wise estimation results

\begin{tabular}{|c|c|c|c|c|c|c|c|c|}
\hline \multirow[b]{2}{*}{ Store } & \multicolumn{4}{|c|}{ Weekdays } & \multicolumn{4}{|c|}{ Weekends } \\
\hline & $\alpha_{i}$ & $\beta_{\mathrm{i}}$ & $\gamma_{\mathrm{i}}$ & $\mathbf{w}_{\mathbf{i}}$ & $\alpha_{i}$ & $\beta_{\mathrm{i}}$ & $\gamma_{\mathrm{i}}$ & $\mathbf{w}_{\mathbf{i}}$ \\
\hline 1 & 15.78 & 0.22 & 14.10 & 65.71 & 24.63 & 0.18 & 20.60 & 45.00 \\
\hline 2 & 22.69 & 0.37 & 13.77 & 74.87 & 22.49 & 0.30 & 20.73 & 51.57 \\
\hline 3 & 17.09 & 0.27 & 14.97 & 115.60 & 22.15 & 0.17 & 23.60 & 75.39 \\
\hline 4 & 15.89 & 0.35 & 11.87 & 40.06 & 22.51 & 0.31 & 19.36 & 19.51 \\
\hline 5 & 15.50 & 0.36 & 13.93 & 22.58 & 22.92 & 0.27 & 20.55 & 19.32 \\
\hline 6 & 18.38 & 0.25 & 14.05 & 108.49 & 21.91 & 0.14 & 22.03 & 80.66 \\
\hline 7 & 17.85 & 0.28 & 9.46 & 74.06 & 19.19 & 0.21 & 14.95 & 43.27 \\
\hline 8 & 18.53 & 0.24 & 10.92 & 80.40 & 24.21 & 0.14 & 17.50 & 52.27 \\
\hline 9 & 13.31 & 0.29 & 10.19 & 75.38 & 18.95 & 0.23 & 16.26 & 44.96 \\
\hline 10 & 15.58 & 0.26 & 10.23 & 77.08 & 18.54 & 0.20 & 16.44 & 39.02 \\
\hline 11 & 13.61 & 0.22 & 15.06 & 26.14 & 17.64 & 0.15 & 23.05 & 22.97 \\
\hline 12 & 14.63 & 0.24 & 11.17 & 68.36 & 19.23 & 0.23 & 16.47 & 38.90 \\
\hline 13 & 16.29 & 0.33 & 9.80 & 58.21 & 18.34 & 0.26 & 13.98 & 39.47 \\
\hline 14 & 16.21 & 0.37 & 11.75 & 81.61 & 24.90 & 0.21 & 18.80 & 54.80 \\
\hline 15 & 11.85 & 0.25 & 9.63 & 22.78 & 13.54 & 0.15 & 14.76 & 20.00 \\
\hline 16 & 19.95 & 0.24 & 7.01 & 50.43 & 22.42 & 0.25 & 12.72 & 37.29 \\
\hline 17 & 15.85 & 0.36 & 12.09 & 71.47 & 21.80 & 0.25 & 18.38 & 55.06 \\
\hline 18 & 15.74 & 0.36 & 11.19 & 54.55 & 19.60 & 0.26 & 17.97 & 40.85 \\
\hline 19 & 18.43 & 0.17 & 10.58 & 58.25 & 20.79 & 0.13 & 16.90 & 41.77 \\
\hline 20 & 19.45 & 0.33 & 9.04 & 56.11 & 20.19 & 0.27 & 12.32 & 38.23 \\
\hline 21 & 16.85 & 0.18 & 18.24 & 74.12 & 23.41 & 0.14 & 27.02 & 49.36 \\
\hline 22 & 13.01 & 0.18 & 11.02 & 59.64 & 17.37 & 0.14 & 16.80 & 44.68 \\
\hline 23 & 14.95 & 0.19 & 19.06 & 54.42 & 20.49 & 0.14 & 13.27 & 29.99 \\
\hline 24 & 13.64 & 0.25 & 19.88 & 28.47 & 21.11 & 0.15 & 21.59 & 24.17 \\
\hline 25 & 14.11 & 0.27 & 15.61 & 45.22 & 17.57 & 0.13 & 25.13 & 27.00 \\
\hline 26 & 15.32 & 0.15 & 11.57 & 55.81 & 22.59 & 0.14 & 17.85 & 29.12 \\
\hline 27 & 19.34 & 0.25 & 11.77 & 45.21 & 27.19 & 0.24 & 18.87 & 25.14 \\
\hline 28 & 12.12 & 0.18 & 12.11 & 45.02 & 21.73 & 0.15 & 19.04 & 20.72 \\
\hline 29 & 18.29 & 0.16 & 13.22 & 40.19 & 24.57 & 0.13 & 19.71 & 24.11 \\
\hline 30 & 15.64 & 0.15 & 12.60 & 29.95 & 20.61 & 0.14 & 19.88 & 21.36 \\
\hline 31 & 12.32 & 0.35 & 13.70 & 60.10 & 20.33 & 0.24 & 20.16 & 32.83 \\
\hline 32 & 18.20 & 0.24 & 11.68 & 74.42 & 26.48 & 0.23 & 26.12 & 37.36 \\
\hline 33 & 11.39 & 0.19 & 10.08 & 68.65 & 13.11 & 0.14 & 22.46 & 39.05 \\
\hline 34 & 20.39 & 0.25 & 18.12 & 22.46 & 23.63 & 0.24 & 13.94 & 19.90 \\
\hline 35 & 14.93 & 0.35 & 10.48 & 67.91 & 18.55 & 0.20 & 16.34 & 42.38 \\
\hline 36 & 20.41 & 0.36 & 9.54 & 67.54 & 23.33 & 0.21 & 15.80 & 43.27 \\
\hline 37 & 11.06 & 0.15 & 16.15 & 47.50 & 18.78 & 0.12 & 23.95 & 24.40 \\
\hline 38 & 19.85 & 0.36 & 10.74 & 51.39 & 22.28 & 0.24 & 16.45 & 27.26 \\
\hline
\end{tabular}




\begin{tabular}{lllllllll}
39 & 16.04 & 0.23 & 15.17 & 60.93 & 21.04 & 0.14 & 18.47 & 50.81 \\
$\mathbf{4 0}$ & 14.62 & 0.27 & 12.14 & 66.53 & 19.88 & 0.14 & 15.74 & 41.93 \\
$\mathbf{4 1}$ & 15.51 & 0.35 & 10.26 & 66.13 & 16.18 & 0.24 & 16.77 & 45.87 \\
\hline
\end{tabular}

Model: $S_{i t}=\alpha_{i} \alpha_{i m}{ }^{a_{m}} \alpha_{i d}{ }^{a_{d}} N_{i t}^{\beta_{i}} e^{-\gamma_{i} / l_{i t}}, \gamma_{i} \alpha_{i} \alpha_{i m}{ }^{a_{m}} \alpha_{i d}{ }^{a_{d}} N_{i t}^{\beta_{i}} e^{-\gamma_{i} / l_{i t}}=w_{i} l_{i t}^{2}$. All estimates significant at $p<0.05$.

A2 Extent of understaffing and overstaffing for individual stores

\begin{tabular}{|c|c|c|c|c|c|}
\hline Store & $\begin{array}{c}\text { Extent of } \\
\text { understaffing } \\
\text { (\% of time) }\end{array}$ & $\begin{array}{c}\text { Average } \\
\text { understaffing } \\
\text { (labor-hour) }\end{array}$ & $\begin{array}{c}\text { Average } \\
\text { understaffing ( } \% \text { of } \\
\text { optimal labor) }\end{array}$ & $\begin{array}{c}\text { Average } \\
\text { overstaffing } \\
\text { (labor-hour) }\end{array}$ & $\begin{array}{c}\text { Average } \\
\text { overstaffing ( } \% \text { of } \\
\text { optimal labor) }\end{array}$ \\
\hline 1 & 28.79 & 3.29 & 29.90 & 1.06 & 20.76 \\
\hline 2 & 33.77 & 3.48 & 31.47 & 1.24 & 13.90 \\
\hline 3 & 33.27 & 3.28 & 29.01 & 1.08 & 13.80 \\
\hline 4 & 35.59 & 3.22 & 30.19 & 1.02 & 17.90 \\
\hline 5 & 35.65 & 3.86 & 29.53 & 1.71 & 18.86 \\
\hline 6 & 41.71 & 3.51 & 32.48 & 1.68 & 40.72 \\
\hline 7 & 32.22 & 4.07 & 30.87 & 0.93 & 14.86 \\
\hline 8 & 29.85 & 4.25 & 44.64 & 1.07 & 14.86 \\
\hline 9 & 25.53 & 3.71 & 32.45 & 0.73 & 20.06 \\
\hline 10 & 31.99 & 3.81 & 31.01 & 0.61 & 15.58 \\
\hline 11 & 20.26 & 2.96 & 31.54 & 0.69 & 22.50 \\
\hline 12 & 28.12 & 2.97 & 28.67 & 0.86 & 24.63 \\
\hline 13 & 31.70 & 2.98 & 33.70 & 1.71 & 23.53 \\
\hline 14 & 34.17 & 3.45 & 30.59 & 1.51 & 34.49 \\
\hline 15 & 34.69 & 3.04 & 32.62 & 1.78 & 18.26 \\
\hline 16 & 30.55 & 3.04 & 26.04 & 1.02 & 22.52 \\
\hline 17 & 22.88 & 3.32 & 25.42 & 1.62 & 34.24 \\
\hline 18 & 21.69 & 3.36 & 34.21 & 1.18 & 34.67 \\
\hline 19 & 26.05 & 3.63 & 32.92 & 0.97 & 27.00 \\
\hline 20 & 35.04 & 3.93 & 32.35 & 0.71 & 23.66 \\
\hline 21 & 37.39 & 2.80 & 30.44 & 0.70 & 27.22 \\
\hline 22 & 30.26 & 3.91 & 33.64 & 0.85 & 32.01 \\
\hline 23 & 26.83 & 3.03 & 34.21 & 0.72 & 16.77 \\
\hline 24 & 36.76 & 3.39 & 30.60 & 1.35 & 28.44 \\
\hline 25 & 35.74 & 3.82 & 29.49 & 1.06 & 22.17 \\
\hline 26 & 41.71 & 3.24 & 30.13 & 1.24 & 34.06 \\
\hline 27 & 34.78 & 3.06 & 31.42 & 0.92 & 15.13 \\
\hline 28 & 20.66 & 2.88 & 28.29 & 0.88 & 19.92 \\
\hline 29 & 25.82 & 2.82 & 33.72 & 1.06 & 22.89 \\
\hline 30 & 25.44 & 2.88 & 30.33 & 1.06 & 19.78 \\
\hline 31 & 23.79 & 3.16 & 27.26 & 1.44 & 40.68 \\
\hline 32 & 24.62 & 2.91 & 27.97 & 0.79 & 18.33 \\
\hline 33 & 22.44 & 3.39 & 35.40 & 1.32 & 35.34 \\
\hline
\end{tabular}




\begin{tabular}{llllll}
\hline $\mathbf{3 4}$ & 36.78 & 2.64 & 28.52 & 0.43 & 17.07 \\
$\mathbf{3 5}$ & 37.87 & 3.83 & 30.36 & 0.72 & 23.03 \\
$\mathbf{3 6}$ & 32.50 & 4.10 & 57.47 & 0.64 & 30.41 \\
$\mathbf{3 7}$ & 24.99 & 3.30 & 28.36 & 1.13 & 24.45 \\
$\mathbf{3 8}$ & 26.57 & 3.25 & 26.19 & 1.14 & 11.77 \\
$\mathbf{3 9}$ & 36.48 & 3.14 & 27.97 & 1.07 & 21.61 \\
$\mathbf{4 0}$ & 22.61 & 3.28 & 31.05 & 1.21 & 31.25 \\
$\mathbf{4 1}$ & 30.55 & 3.16 & 31.29 & 0.99 & 26.41 \\
\hline
\end{tabular}

A3 Estimation results for the of model with hourly observations

\begin{tabular}{ccccccccc}
\hline \multicolumn{4}{c}{ Weekdays } & \multicolumn{5}{c}{ Weekends } \\
\hline Parameter & Average & Std Dev & Min & Max & Average & Std Dev & Min & Max \\
$\boldsymbol{\alpha}_{\boldsymbol{i}}$ & 21.36 & 4.01 & 12.82 & 27.65 & 26.81 & 4.85 & 14.32 & 31.41 \\
$\boldsymbol{\beta}_{\boldsymbol{i}}$ & 0.29 & 0.10 & 0.10 & 0.65 & 0.21 & 0.06 & 0.11 & 0.52 \\
$\boldsymbol{\gamma}_{\boldsymbol{i}}$ & 10.69 & 2.84 & 5.87 & 17.69 & 28.65 & 8.11 & 19.41 & 45.28 \\
\hline \multirow{2}{*}{ Estimates for the model: $S_{i t h}=\alpha_{i} \alpha_{i m}{ }^{{ }^{2}}{ }^{2} \alpha_{i d}{ }^{a} N_{i t h} N_{i} e^{-\gamma_{i} / l_{i t h}}, \gamma_{i} \alpha_{i} \alpha_{i m}{ }^{a_{m}} \alpha_{i d}{ }^{a_{d}} N_{i t h}^{\beta_{i}} e^{-\gamma_{i} / l_{i t h}}=w_{i} l_{i t h}^{2}$}
\end{tabular}

